\title{
Chapter 9 \\ Applying a Standards-Based Approach to Reduce Maternal Mortality and Improve Maternal and Neonatal Services in Mozambique
}

\author{
Edgar Necochea, Maria da Luz Vaz, Ernestina David, and Jim Ricca
}

\begin{abstract}
This case demonstrates how a Quality Improvement (QI) initiative systematically improved the delivery of maternal and newborn health services at a large number of health-care facilities in Mozambique, with limited external assistance (e.g., external supervision or technical assistance after the initial 6 months), despite facing the challenges common to many low-income settings. In particular, this case examines the organization of a QI effort, including the formation of QI teams, enhancement of data collection to document QI activities, and national scaleup of a QI intervention. The QI intervention applied relied on provider training provider training on evidence-based standards, assessment of compliance with the performance standards, strengthening of the health management information system to enable tracking of selected quality-of-care indicators, and formation of facility-level QI teams to lead the implementation of the standards through performance assessments and action plans to address performance gaps, followed by recognition ceremonies if the facility achieved a high level of compliance with the standards based on an external assessment.
\end{abstract}

Keywords Antenatal Care · Emergency Obstetric Care · Labor and Delivery · Maternal and Neonatal Care · Maternal and Neonatal Mortality · Mozambique · Postnatal Care $\cdot$ Standards-Based Management and Recognition

\footnotetext{
E. Necochea $(\square)$

Jhpiego, Baltimore, MD, USA

e-mail: Edgar.Necochea@jhpiego.org

M. da Luz Vaz · E. David

Jhpiego, Maputo, Mozambique

J. Ricca

Jhpiego/Maternal and Child Survival Project, Baltimore, MD, USA

(C) University Research Co., LLC 2020

L. R. Marquez (ed.), Improving Health Care in Low- and Middle-Income

Countries, https://doi.org/10.1007/978-3-030-43112-9_9
} 


\section{Background and Setting}

Although more than $50 \%$ of deliveries in Mozambique occur at health facilities, high maternal mortality rates - an estimated 506 deaths per 100,000 live births in 2014 - have persisted as a public health issue. To address concerns about the quality of public health services, the Mozambique Ministry of Health ( $\mathrm{MOH})$, in partnership with a USAID-funded project, launched in 2009 a maternal mortality reduction initiative intended to reduce high mortality rates and improve facility-based maternal and neonatal care. Known as the Model Maternities Initiative (MMI), the initiative began with 34 maternities. The main criteria for the selection of the initial maternities, made jointly by the $\mathrm{MOH}$ and the supporting partner, were high volume of deliveries and being the practice sites for midwifery students. After 5 years, by 2014, the initiative had expanded to 120 maternities, about half of all maternities in the country. Approximately one-third of all the institutional deliveries take place in these facilities.

The MMI draws on the Standards-Based Management and Recognition® (SBM$\mathrm{R}())$ approach to quality improvement (QI), which uses practical and educational assessment tools to embed the evidence-based service delivery standards (Necochea and Bossemeyer 2005). The tools drive a systematic process to spearhead, roll out, and scale up a QI process at the facility and national levels.

Since 2004, the approach has been applied in Mozambique in areas such as infection prevention and inpatient care, to promote adoption of evidence-based care. Because of its national scope, the infection prevention initiative was previously implemented in all the participating maternities, while the inpatient care one was conducted in the medical and surgical wards in some of the hospitals where the maternities are located. The provincial- and district-level MOH staff had supported both experiences through supervision and resource allocation and were familiar with the SBM-R®. The MOH officials' and facility health-care providers' familiarity with SBM-R® helped to pave the way for the introduction of the maternal mortality reduction effort.

At the start of the MMI, the major obstacles to the quality of maternal and newborn care in Mozambique included a severe shortage of the doctors and nurses who provide support during the antenatal, labor and delivery, and postnatal care at the health facilities, as well as the variable competence of these providers. Other constraints on the quality of care included infrastructure inadequacies and shortcomings (e.g., limited space for labor and delivery rooms), lack of material resources and equipment, and weak preservice training and supervision systems (MOH 2008, 2016). These challenges had to be considered by the $\mathrm{MOH}$ and supporting partner when the MMI intervention was designed and implemented so that it could eventually be scaled up nationwide. For instance, the method and tools were simplified as much as possible to make them less time consuming to apply by the staff already overloaded with patient care; the content was organized to serve as a job aid; and emphasis was placed on resource mobilization skills. 


\section{Designing and Organizing the Improvement Effort}

\section{Approach and Strategy}

Following the SBM-R® process, the MMI took a four-step approach, as depicted in Fig. 9.1:

1. Development of performance standards

2. Implementation of the standards through facility assessments and improvement actions

3. Measurement of progress through review of the repeated assessments and tracking of selected indicators

4. Recognition of achievements

The design of the improvement effort is focused on the development of the performance standards, the training of the health-care providers in the standards, the implementation of assessments and correction of gaps, and strengthening the health management information system to support measuring progress.

\section{Development of the Performance Standards}

In one of the initiative's first steps, a group of technical experts comprised of leaders from the $\mathrm{MOH}$ and the USAID-funded project convened to develop assessment tools intended to operationalize performance standards. The group reviewed the evidence for the good practices in the four areas of the maternal and newborn care: antenatal care, normal labor and delivery, emergency obstetric care, and postnatal care. The technical experts consulted the recommendations and materials issued by the World Health Organization (WHO) and the guides on the Integrated Management of Pregnancy and Childbirth (IMPAC), as well as the national guidelines and

Fig. 9.1 The MMI method model

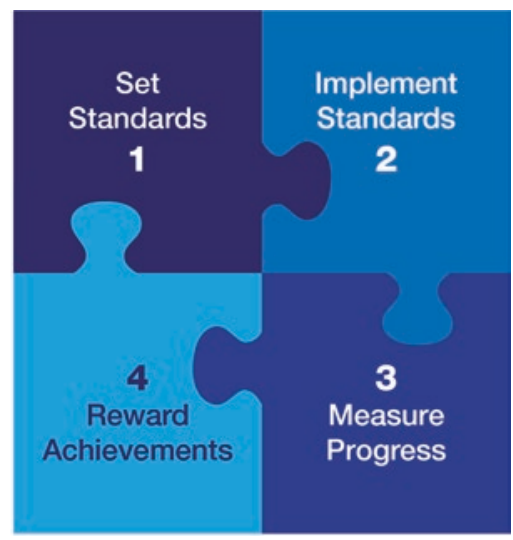


protocols. They also considered other factors that affect the implementation of these kinds of evidence-based practices, including the available resources; facility management; community information, education, and involvement; and the instruction of the student health-care workers who do practical rotations at the maternities. For instance, standards on the resources needed for the provision of clinical care, the basic management support functions, and the teaching process and involvement of midwifery students were developed specifically to strengthen these areas. All the standards were consistent with the Mozambique national guidelines for maternal and neonatal care. Table 9.1 lists some examples of the key evidence-based practices identified and considered by the group.

The technical group used this information to develop the performance standards and organized them into nine areas, listed in Table 9.2. Reflecting a holistic view of quality, the final standards included high-impact, effective, evidence-based practices, as well as guidelines, to ensure safety for the patients and providers, respectful and humanized care, and facility readiness. The group developed a list of specific measurable tasks - verification criteria -intended to be used in a checklist format. As illustrated by the example in Fig. 9.2, the group developed a form to assess whether the performance standards in each area were being met. To successfully achieve a performance standard, a health facility had to meet all of the verification criteria for that standard. Across the nine areas, 81 standards and a total of 511 verification criteria were defined.

Table 9.1 Evidence-based practices promoted by the MMI

\begin{tabular}{|c|c|}
\hline Service area & Evidence-based practices \\
\hline Antenatal care & $\begin{array}{l}\text { - Minimum of four antenatal care visits } \\
\text { - Services should include provision of iron folate supplements, prevention } \\
\text { of mother-to-child transmission of HIV, and preparedness and planning } \\
\text { for obstetric complications }\end{array}$ \\
\hline $\begin{array}{l}\text { Normal labor } \\
\text { and delivery }\end{array}$ & $\begin{array}{l}\text { - Consistent use of partograph } \\
\text { - Active management of the third stage of labor (AMTSL) } \\
\text { - Skin-to-skin contact with mother immediately after delivery } \\
\text { - Breastfeeding within } 1 \text { hour of delivery } \\
\text { - Immediate postpartum family planning }\end{array}$ \\
\hline $\begin{array}{l}\text { Emergency } \\
\text { obstetric care }\end{array}$ & $\begin{array}{l}\text { - Provision of the basic emergency obstetric and neonatal care } \\
\text { - Timely referral for comprehensive emergency obstetric and neonatal care }\end{array}$ \\
\hline Postnatal care & $\begin{array}{l}\text { - Three postnatal care visits for the mother and newborn at 2-3 days, } \\
7 \text { days, and } 21-28 \text { days postpartum } \\
\text { - Promotion of long-acting family planning methods }\end{array}$ \\
\hline
\end{tabular}

${ }^{a}$ Basic emergency obstetric and neonatal care includes parenteral treatment of infection with antibiotics, parenteral treatment of severe preeclampsia or eclampsia (e.g., magnesium sulfate), treatment of postpartum hemorrhage (e.g., uterotonics), manual vacuum aspiration of the retained products of conception, assisted vaginal delivery (e.g., vacuum-assisted delivery), manual removal of placenta, and newborn resuscitation

bIn addition to the elements included in the basic emergency obstetric and neonatal care, comprehensive emergency obstetric and neonatal care includes surgical capability, such as, anesthesia (e.g., cesarean section) and blood transfusion 
Table 9.2 The MMI performance standards, by area

\begin{tabular}{l|l|l|l}
\hline & Area & $\begin{array}{l}\text { Number of } \\
\text { standards }\end{array}$ & $\begin{array}{l}\text { Number of verification } \\
\text { criteria }\end{array}$ \\
\hline 1 & Management of maternal and neonatal services & 8 & 27 \\
\hline 2 & Information, monitoring, and evaluation & 5 & 20 \\
\hline 3 & $\begin{array}{l}\text { Resources: human, infrastructure, and } \\
\text { commodities }\end{array}$ & 4 & 24 \\
\hline 4 & Working conditions and safety & 8 & 18 \\
\hline 5 & Health education and community involvement & 4 & 35 \\
\hline 6 & Antenatal and postnatal care & 14 & 96 \\
\hline 7 & $\begin{array}{l}\text { Care during normal labor, delivery, and the } \\
\text { immediate postpartum period }\end{array}$ & 24 & 188 \\
\hline 8 & $\begin{array}{l}\text { Management of obstetric and newborn } \\
\text { complications }\end{array}$ & 10 & 86 \\
\hline 9 & Teaching process & 4 & 17 \\
\hline & Total & 81 & 511 \\
\hline
\end{tabular}

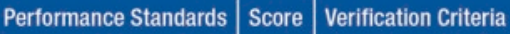

\section{\begin{tabular}{l|l|l|l} 
Yes & No & N/A & Comments
\end{tabular}}

1. The facility manager ensures the minimum supportive environment for ANC service.

\begin{tabular}{|c|c|c|c|}
\hline $\begin{array}{l}\text { Ensures in the examination area the } \\
\text { existence of: a door that can be closed } \\
\text { and good illumination and ventilation } \\
\text { (fan/heating) }\end{array}$ & $\square$ & $\square$ & $\square$ \\
\hline $\begin{array}{l}\text { Ensures the existence of clients' and } \\
\text { staff washroom in or near the ANC clinic } \\
\text { with available water, soap and paper } \\
\text { towels and with a functioning toilet }\end{array}$ & $\square$ & $\square$ & $\square$ \\
\hline $\begin{array}{l}\text { Ensures the existence of working } \\
\text { washbasin with faucet or bucket with lid } \\
\text { in the examination room }\end{array}$ & $\square$ & $\square$ & $\square$ \\
\hline $\begin{array}{l}\text { Ensures that the essential furniture } \\
\text { and minimum required equipment are } \\
\text { available }\end{array}$ & $\square$ & $\square$ & $\square$ \\
\hline $\begin{array}{l}\text { Ensures that the minimum required } \\
\text { infection prevention materials are } \\
\text { available }\end{array}$ & $\square$ & $\square$ & $\square$ \\
\hline $\begin{array}{l}\text { Ensures that the floors, walls, furniture, } \\
\text { equipment, surfaces of the waiting } \\
\text { area, consultation rooms and clients' } \\
\text { washroom are clean }\end{array}$ & $\square$ & $\square$ & $\square$ \\
\hline $\begin{array}{l}\text { Ensures that the essential tests, drugs } \\
\text { and vaccines are available }\end{array}$ & $\square$ & $\square$ & $\square$ \\
\hline $\begin{array}{l}\text { Ensures that the minimum required } \\
\text { disposable materials, forms and } \\
\text { registers are available }\end{array}$ & $\square$ & $\square$ & $\square$ \\
\hline $\begin{array}{l}\text { Asks about or observes if the woman } \\
\text { has or has had: vaginal bleeding, } \\
\text { breathing problem, fever, severe } \\
\text { headache/blurred vision, severe } \\
\text { abdominal pain and/or convulsions/loss } \\
\text { of consciousness }\end{array}$ & $\square$ & $\square$ & $\square$ \\
\hline $\begin{array}{l}\text { Assures immediate attention by a skilled } \\
\text { provider in the event of any of the above } \\
\text { signs }\end{array}$ & $\square$ & $\square$ & $\square$ \\
\hline
\end{tabular}

2. The provider prepares and checks the ANC clinic/ examination areas before starting daily consultations. receives the pregnant woman conducts a rapid initial evaluation at the first contact.
3. The person who

(fan/heating)

Ensures the existence of clients' and steft washroom in or near the ANC clinic

Ensures the existence of working washbasin with faucet or bucket with lid in the examination room

Ensures that the essential furniture and minimum required equipment are available

Ensures that the floors, walls, furniture, equipment, surfaces of the waiting area, consultation rooms and clients' washroom are clean

Ensures that the essential tests, drugs and vaccines are available

Ensures that the minimum required disposable materials, forms and registers are available

Asks about or observes if the woman has or has had: vaginal bleeding breathing problem, fever, severe 列 consciousness provider in the event of any of the above

Fig. 9.2 Excerpt from the assessment tool for the antenatal care performance standards 
The project and $\mathrm{MOH}$ technical teams, which included national and provincial officials and frontline providers, discussed the proposed standards in two nationallevel workshops, which also included representatives from the Mozambican Association of Obstetricians and Gynaecologists. The tools were then pretested in a few settings, and additional input was collected from frontline providers and managers. The Maternal and Child Health Directorate at the $\mathrm{MOH}$ reviewed and approved the final MMI assessment tool with the 81 performance standards.

\section{The Provider Training}

The USAID-funded project recognized that the evidence-based standards and rationale for the newly developed standards had to be disseminated and discussed with the providers in order to facilitate their adoption at the facility level. Updating providers' technical knowledge and skills was essential because many were unfamiliar with the recommended clinical practices, and their level of training and technical skills varied.

Competency-based training served as a critical component of the initiative. The project and $\mathrm{MOH}$ technical staff conducted a series of 10-day competencybased training workshops for two to four providers from each participating facility. These workshops were implemented at the provincial level at the beginning of the year every time a new group of maternities was incorporated into the initiative. Facility managers selected these providers, who were usually maternal and child nurses (the equivalent of midwives). The course covered basic maternal and neonatal care practices with an emphasis on deliveries and management of complications.

During the last day of each workshop, trainers introduced the initiative assessment tool and explained the QI process. They instructed the providers on the following:

- How to use the tool to conduct a facility assessment

- How to analyze the results to identify gaps in performance (standards/criteria not met)

- How to identify and design corrective measures addressing issues of competency, lack of resources, and lack of motivation

- How to implement an action plan with corrective measures including all members of the team

- How to measure progress through periodic internal assessments and tracking of selected indicators

- How to implement recognition activities for partial and comprehensive achievements

Over 5 years, the project trained close to 1560 health professionals in maternal and neonatal care. Provincial health offices often decided to also implement the 
clinical training in facilities not participating in the initiative. In these facilities, representing around $15 \%$ of all the staff trained, the workshop excluded the QI portion. Coaches also participated in the trainings for their provinces and, in addition, held quarterly meetings to review the implementation process and discuss approaches to overcome the challenges and foster change.

\section{Strengthening the Health Management Information System}

The USAID-funded project worked with the MOH and partners (WHO, UNICEF) to enhance and strengthen the Mozambique's Health Management Information System (HMIS), so that it would be possible to track the selected quality-of-care indicators relevant to the MMI. In 2011, the MOH revised the reproductive, maternal, newborn, and child health component of the HMIS to collect the additional data on quality of care, respectful care, and direct and indirect obstetric complications and maternal deaths. New maternity registers were created to collect information on the key clinical practices promoted by the MMI, including the active management of the third stage of labor, treatment of eclampsia with magnesium sulfate, use of partograph, family companions present at delivery, immediate skin-to-skin contact with the mother after delivery, and breastfeeding within the first hour after birth. During the initial 10-day workshops, the MMI facility staff were trained on the modified registries and asked to track the newly recorded quality indicators (as well as, institutional maternal deaths) and to provide routine reports to the Maternal and Child Health Directorate at the $\mathrm{MOH}$. The $\mathrm{MOH}$ and project provincial supervisors checked the data for quality and consistency.

\section{Carrying Out the Improvement Effort}

\section{The Formation of the QI Teams}

The QI process took place at the facility level with the participation of health-care providers, as well as, the facility managers. In Mozambique, the providers who attended the MMI training workshops became the core members of the facility QI team, along with the other providers and key managers. The number of members of each team varied, but in general, they included 5-10 facility staff. These teams, which were responsible for overseeing the entire QI process at their facilities through periodic monthly meetings, operated with limited external assistance. In each of the Mozambique's 10 provinces, one coach - a midwife hired by the USAID-funded project - supervised and supported the facility QI teams, making quarterly visits to the facilities and involving the $\mathrm{MOH}$ provincial technical staff as much as possible. Distant support was also provided through telephone. 
Each of the provincial coaches oversaw approximately 10-12 maternities. The most important duty of a provincial coach was to help the facility QI team with the improvement process, including participating in the assessments when possible, reviewing progress with the teams, providing guidance on the gap analysis and improvement tasks, reinforcing the training on the evidence-based practices, facilitating support from the facility managers, conducting quality assurance of the data collected on the indicators, and promoting learning exchanges through the involvement of the facility team members in the external assessments of the other facilities. The provincial coaches, in turn, received support from the five MMI regional coaches, also midwives. Often, but not always, the provincial coaches provided support for the baseline service assessment and regularly reported on the activities in their provinces, including the progress on assessments and evolution of the selected indicators. One national coordinator of the initiative, a medical doctor specialist in obstetrics and gynecology, provided support to the regional coaches working in coordination with the $\mathrm{MOH}$ Maternal and Child Health Directorate.

\section{Implementing the Standards Through Facility Assessments, Action Plans, and Change Management}

Figure 9.3 depicts the facility-level improvement process. The facility QI teams began the process by conducting a baseline assessment on the maternal and newborn health services using the MMI assessment tool (an excerpt of which is provided for antenatal care performance standards in Table 9.2). The assessment required the teams to record direct observations concerning the infrastructure and processes of care, review the records, and interview the staff in order to determine whether the facility met each of the verification criteria listed in the MMI

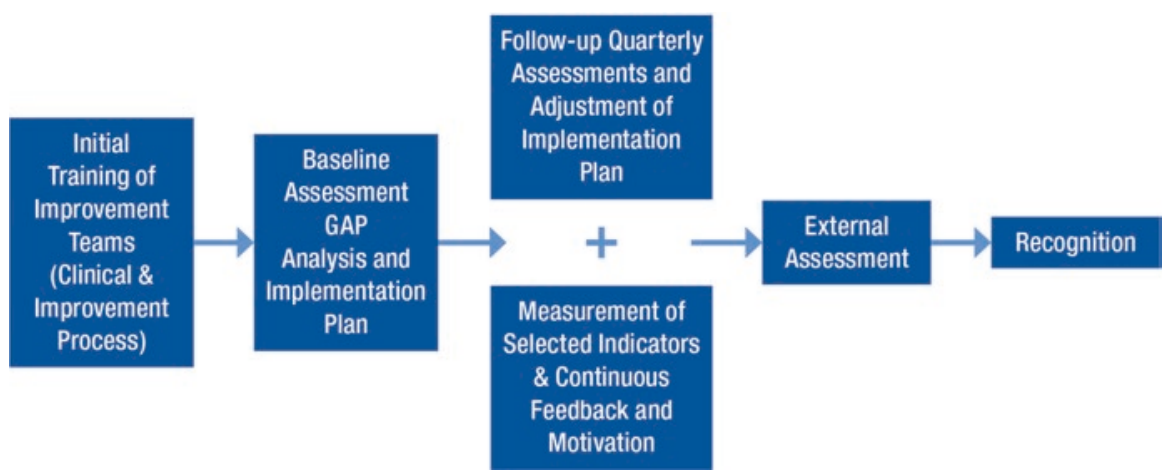

Fig. 9.3 The MMI improvement process at the facility level 
assessment tool. Typically, each assessment took 2 days to complete and included observations of at least three deliveries. After collating and analyzing the results, the team identified the unmet standards as the performance gaps and developed an action plan to correct those gaps. Whenever the assessments coincided with a visit by the provincial coach, they then helped with the analysis of the results, offering guidance on feasible solutions, including those already adopted in the other maternities.

Because some performance gaps in facilities often can be addressed fairly quickly and easily, the initiative focused on implementing rapid interventions rather than on in-depth analysis of complex problems. The interventions were aimed at correcting simple and clear shortcomings in quality, for example, lack of cleanliness, failure to practice basic infection prevention, disorganized work space, and minor infrastructure disrepair. Teams were instructed to focus initially on the rapid interventions rather than on the analysis of the complex problems. A key theory underlying the approach is that promoting rapid and visible changes at the maternities quickly fosters a sense of empowerment and increases self-efficacy, preparing the facility QI teams to gradually undertake more complex tasks.

Improvements in the facilities attracted the attention and support of the managers and generated enthusiasm among the other providers, who then joined the improvement efforts. At one facility, for example, the team observed a lack of privacy in the maternity for clients accompanied by companions. The team members mobilized support for the placement of curtains between maternity beds. While pursuing the curtains (the team obtained support from the local sugar-cane plantation and refinery to finance the purchase of the curtains) for increased privacy, providers discussed the need to address other aspects of clients' rights, such as, respectful care and the right to adopt positions at birth according to cultural preferences. After the curtains were put in place, this visible improvement prompted the team to make other improvements in cleanliness and the organization of the maternity ward. The facility manager was happy with the improvements and called the maternity the "best service" in the health facility, reinforcing the positive momentum for change. To address more complex issues, the teams met and more carefully analyzed causes and potential solutions.

The facility teams repeated the assessments every 3-6 months in order to measure progress and identify additional performance gaps that needed to be addressed. Because $\mathrm{MOH}$ policies encouraged community involvement, several facilities shared the results of the performance assessments with the facility comanagement committees. These comanagement committees, promoted by the $\mathrm{MOH}$, included traditional leaders and active community members. Their function was to provide the community perspective on health care, participate in improvement activities, and mobilize community support. The facility QI teams acted quickly to address the gaps that could be corrected through local action or with the local resources (for instance, reorganization of spaces, hygiene and cleanliness, minor repairs, and better coordination with management) and then move on to the more difficult challenges, such as, obtaining additional supplies, remodeling infrastructure, expediting the flow of care, and making behavioral 
changes needed to adopt recommended practices (e.g., encouraging providers to use partographs to identify danger signs during labor and encouraging women to adopt early breastfeeding). Administrators often expedited the process by offering additional support, for example, by providing cleaning and medical supplies or by initiating repairs.

When proposed solutions were outside of the facility's purview, teams could request support from the $\mathrm{MOH}$ provincial directorate or from the USAID-funded project to address a performance gap. For example, the project provided support for minor renovations at some facilities, such as, painting, fixing water pipes, and installing sinks.

Supported by the project, some teams organized visits to other facilities to exchange experiences, which helped motivate staff participating in the MMI. The highest-performing members of the facility QI teams were selected to join the external assessment teams that visited and rated other maternities; providers perceived this recognition as an incentive.

Facility managers, in general, favorably reviewed the QI process. They commented that it helped improved the organization of services and encouraged adoption of the best practices for deliveries and obstetric and neonatal complications. They noted that the providers spoke "the same language" after they were updated and adopted the standard practices.

The providers reported that, although they felt that they were being "observed and watched", they perceived that the actions emanated from a supportive and nonjudgmental viewpoint. The standardized tools helped to improve supervision and substantiated requests for additional support from the provincial and national $\mathrm{MOH}$ levels. They also noted that patients' anxiety decreased as a result of the adoption of respectful care practices, such as, allowing clients to have companions present. The nursing and other medical students also are benefited because the maternities serve as clinical practice sites, and improvements in the facility practices are carried over to improve teaching.

\section{Improvement Efforts at Xai-Xai Provincial Hospital, Mozambique}

Xai Xai Provincial Hospital had been implementing the SBM-R® approach in the area of infection prevention and control for nearly 5 years, achieving successive recognition for their high level of compliance with the standards. When the MMI was launched by the MOH in 2009 using the same approach, a baseline performance assessment using the MMI standard tool was conducted in the hospital. The hospital initially had poor compliance with the standards $(24.1 \%$ on baseline assessment); however, the hospital was determined to improve the maternity and immediately began to implement interventions to introduce and strengthen the high-impact practices and humanized care stipulated in the standards. Compliance 
Table 9.3 Selected indicators, performance assessments, and maternal mortality, Xai-Xai Provincial Hospital, Mozambique (2009-2014)

\begin{tabular}{|c|c|c|c|c|c|c|c|}
\hline & 2009 & 2010 & 2011 & 2012 & 2013 & 2014 & 2015 \\
\hline $\begin{array}{l}\text { Maternal deaths, all } \\
\text { causes }\end{array}$ & & 15 & 12 & 10 & 8 & 12 & 10 \\
\hline Companion during birth & & \multirow{5}{*}{$\begin{array}{l}\text { These indicators were } \\
\text { not reported in the } \\
\text { MOH HMIS as of } \\
2010\end{array}$} & $2 \%$ & $2 \%$ & $6 \%$ & $72 \%$ & $76 \%$ \\
\hline $\begin{array}{l}\text { Active management of } \\
\text { the third stage of labor }\end{array}$ & & & $81 \%$ & $85 \%$ & $81 \%$ & $80 \%$ & $71 \%$ \\
\hline $\begin{array}{l}\text { Delivery in vertical or } \\
\text { semi vertical position }\end{array}$ & & & $<1 \%$ & $<1 \%$ & $1 \%$ & $3 \%$ & $1.4 \%$ \\
\hline $\begin{array}{l}\text { Mother-newborn } \\
\text { skin-to-skin contact }\end{array}$ & & & $86 \%$ & $88 \%$ & $86 \%$ & $85 \%$ & $80 \%$ \\
\hline $\begin{array}{l}\text { Immediate initiation of } \\
\text { breastfeeding (within the } \\
\text { first hour) }\end{array}$ & & & $87 \%$ & $89 \%$ & $87 \%$ & $85 \%$ & $81 \%$ \\
\hline $\begin{array}{l}\text { Compliance with the } \\
\text { MMI performance } \\
\text { standards during } \\
\text { assessment }^{\mathrm{a}}\end{array}$ & $24.1 \%$ & $81.7 \%$ & $51.7 \%$ & $72.9 \%$ & $83.9 \%$ & $98.4 \%$ & N/A \\
\hline
\end{tabular}

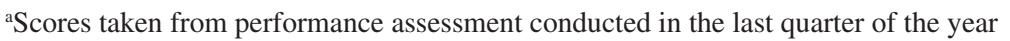

with standards improved markedly in the subsequent performance assessments (Table 9.3).

In 2011, the MOH, with the support of the USAID-funded project, introduced modifications to the HMIS, including inclusion of the key quality-of-care indicators, which allowed for tracking of quality-related maternal and neonatal care practices. Tracking of selected indicators in the modified HMIS showed that some practices at Xai-Xai, such as, AMTSL, skin-to-skin newborn care, and early initiation of breastfeeding, had already reached high levels of compliance by 2011: these practices were not implemented before 2010.

Other practices, such as, presence of a companion during birth, required more consistent leadership, teamwork, and community involvement. The hospital considered that birth companions were a good strategy to prevent or limit abuse and promote a better client-family-provider interaction. The team concluded that critical constraints were the physical area of the maternity (too small to accommodate companions) and the attitude of clients and providers. After discussing several options, the team decided to remodel the physical space of the maternity (and got external support for this) and promoted community-provider meetings and discussions on the process of care for deliveries. After the maternity was renovated and expanded in the early part of 2014 to allow companions to be present during labor and delivery, relatives were more open to participate as companions and the providers incorporated relatives as helpers for the care of mothers. Using a similar approach, Xai-Xai also undertook other key improvements related to clinical practices. 


\section{The Role of Mid-level Managers in the Health System}

The provincial $\mathrm{MOH}$ managers supported the initiative and its expansion. They promoted and coordinated the participation of their technical staff in supervision and assessments and were involved in training activities. The provincial managers participated in and approved the selection of the project's provincial coaches or supervisors and provided them with office space in the provincial health directorate offices. Often, the provincial managers, in an effort to maximize the intervention's benefits, involved maternities that were not part of the MMI in the training activities. The snapshot from a participating hospital director (see Box 9.1) illustrates the process from a facility perspective and highlights the relevance of respectful care.

\section{Box 9.1 A Doctor Tells Her Story}

I am Mozambican, 59 years old, and mother of three women and a girl aged 42, 39, 20, and 5 years. My country is young; it has been independent for 41 years. Particularly at the beginning, health services were scarce and inadequate for a population with many health needs. I was also young when I got pregnant, I was 16 years old. Even when I was a child or adolescent with an unwanted pregnancy, it happened without complications. When my delivery date became near, my problem was where to deliver my baby. I was extremely afraid of the local hospital. As a child and teenager, I had heard many stories about pregnancy and deliveries: that it was very painful, that I could not eat eggs because the baby would not get out of my womb, that health providers at the hospital maternity were cold and insensitive, and that the care they provided was not good. In particular, what I heard about one of the most experienced midwives at the hospital made me shiver. This woman was famous because of her cruelty to the women under her care: she insulted and even physically abused and mistreated them.

For this reason, when the time of my delivery came, I was so afraid of going to the hospital, that I had my baby at home, helped by my mother. My baby weighed $3.8 \mathrm{~kg}$ ( $8 \mathrm{lbs}, 6 \mathrm{oz}$ ) and was born with the umbilical cord wrapped around her neck. In spite of this complication, my baby fortunately was born normally.

When I grew up and decided to become a medical doctor, I promised myself that nobody under my care would experience the same as I did. Over the years, I became director of a provincial hospital with 53 maternity beds.

That is why, when I learned about the program started by the Ministry of Health of Mozambique ... to make maternal health and deliveries safer, respectful, humanized, and successful, I decidedly embraced it and mobilized 


\section{Box 9.1 (continued)}

my staff to implement it. We did not want any more abuse and fear of the hospital. We put in practice standards of care through continuous assessments, staff meetings, and supervision. ... We implemented practices, such as, allowing a companion for women in labor and delivery, respect for their preferences regarding position at birth, privacy, freedom of movement when in labor, early breastfeeding, mother and baby skin contact, and others.

We worked hard for 6 years. At the beginning, it was difficult: the population did not believe in our "sudden" change of attitude. Companions did not want to see blood and did not want to be present, in spite of the requests of their patients. So, we involved our hospital-community committee (formed by community leaders, religious leaders, traditional providers, and women's and youth organizations) to better communicate with our clients. I do not believe our work has finished, but we have made visible progress: our staff has a better and more respectful attitude and appears more motivated, there are fewer abuses, including illegal charges to patients, more satisfaction expressed by mothers and families, fewer complaints by clients and the community, and better teaching for new midwifery and nursing students. The community participates actively and reports any abuses to our joint committee. We have also reduced the number of maternal deaths from 15 in 2010 to 10 in 2015.

\section{The Power of Recognition}

Providing public recognition - the final step in the initiative's QI process - played a key role in motivating and engaging providers. Once an internal assessment showed that a maternity was complying with $80 \%$ or more of all the maternal and neonatal health standards, the facility QI team could apply for recognition. An external assessment team consisting of central- and provincial-level $\mathrm{MOH}$ technical staff and project representatives would visit the facility and use the initiative's tool to assess performance.

If the external assessment verified a high level of compliance with the standards, the $\mathrm{MOH}$ officials will formally organize a ceremony at the facility to publicly honor the achievement. The recognition ceremonies are a visit to the maternity, interactions with clients, speeches by the authorities and community leaders, stage performance by maternity staff (theater, dances), and awarding of plaque.

These ceremonies, in which all the facility staff would participate, proved to be powerful motivators. Facilities were motivated by an opportunity to gain public recognition and will strive to achieve the level required. They value the presence of high-level authorities and the community at the ceremonies. At the same time, the ceremonies helped to reinforce leaders' commitment and support for maternal and neonatal health. 


\section{The Implementation Challenges}

Levels of commitment and enthusiasm varied among the teams, as did the impact of their efforts. The facility improvement teams who were proactive quickly produced visible and significant improvements in the use of evidence-based practices and respectful care. Other teams delayed the implementation of the QI and required additional guidance and support from the external supervisors and facility managers before getting started. Still other teams were reluctant to undertake improvements because they often feel their workload was already too heavy and the constraints imposed by infrastructure, supplies, and human resources were too great. Adoption of the QI process was slower and more difficult when facility staff perceived it as being promoted by an external nongovernmental organization. In contrast, when the MOH supervisors were involved, they lent more legitimacy to the process.

The facility managers noted a variety of problems during the initial implementation of the intervention. At the beginning, some providers were not inclined to adopt the evidence-based practices promoted by the initiative; in these cases, continuous on-thejob training proved important to reinforce the best practices. Human resources shortages and staff rotation also posed significant barriers to the adoption of best practices. Time constraints, aggravated by staff shortages, often made the adoption of the QI processes more difficult. Further, in what was most likely an effort to show progress, some facility improvement teams are too lenient in their maternity assessment. After the external assessment teams highlighted the inaccuracies and the providers realized that the purpose was not punitive, the teams gradually began to do more accurate assessments.

\section{The Measurement and Results}

Modifications and enhancements to the HMIS enabled the Model Maternities' Initiative to routinely collect quality-of-care data that is not accessible to most of the similar initiatives. The facility QI teams, the MMI leadership, and the MOH relied on the three types of data to measure quality improvement at participating maternities:

1. Self-reported performance, based on the facility assessments performed by the facility teams

2. Clinical practice indicators, based on the data from the facility registers

3. Maternal mortality, also from the HMIS registries

\section{The Provider and Facility Performance}

Regular internal assessments of facility performance were a core activity for the QI approach used in Mozambique. The facility QI teams conducted an assessment every 3-6 months (which took around 2 days to complete) and used the data to calculate the percentage of the performance standards achieved in each of the nine areas. The teams reported the results of these internal assessments to the project's 


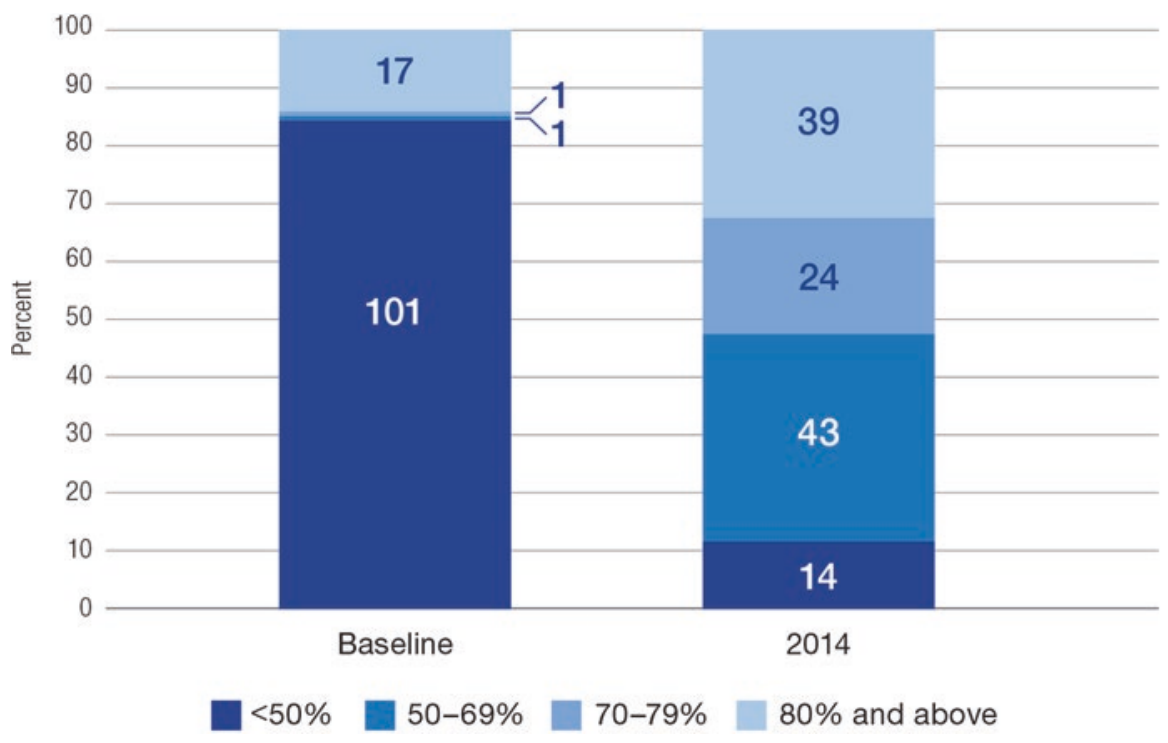

Fig. 9.4 Number of maternities $(n=120)$, by percentage of performance standards met at the baseline and at the end of the MMI process

monitoring and evaluation unit, which periodically consolidated and reported them to the $\mathrm{MOH}$. The provincial coaches were responsible for reviewing the quality of the data. Provincial directorates analyzed the data from their facilities and, guided by that information, implemented the appropriate support measures.

Changes did not occur at the same pace or with the same magnitude in every facility. Some maternities excelled, most made significant improvements, while others lagged behind. Data are available for 1-13 assessments at each maternity, depending on the year they joined the initiative; a new group of 25-30 maternities was added each year. At baseline, four-fifths of maternities complied with less than $50 \%$ of the performance standards (Fig. 9.4). Toward the end of the project, the vast majority of maternities had achieved at least $50 \%$ of standards, and one-third had achieved at least $80 \%$ of standards. Compliance remained below $50 \%$ at only $12 \%$ of maternities, typically those that had only recently launched the MMI intervention. Taken as a whole, the improvements observed were sufficient to have an impact on the prevalence of evidence-based practices and ultimately on the institutional maternal mortality ratio, as shown in Fig. 9.5.

\section{The Clinical Practice Indicators}

The MMI facility QI teams monitored relevant clinical practice indicators, using data from the revised $\mathrm{MOH}$ facility register. Team members entered and reported monthly information on selected indicators related to preselected evidence-based and respectful care practices: 


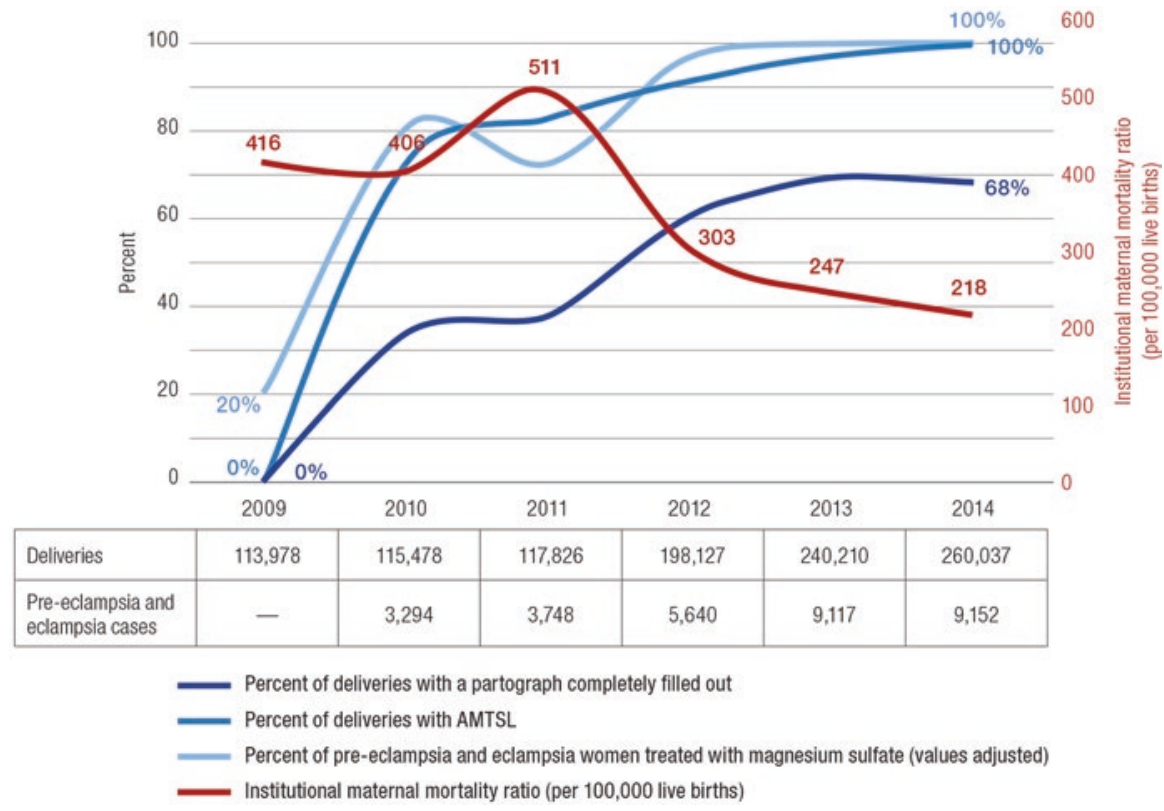

Fig. 9.5 Improvement in selected high-impact maternal care practices and maternal mortality ratio

- Births with active management of the third stage of labor (AMTSL)

- Eclampsia cases treated with magnesium sulfate

- Deliveries with a partograph completely filled in

- Number of obstetric complications

- Deliveries with a family companion present

- Newborns with immediate skin-to-skin contact with the mother

- Newborns breastfed within the first hour

Provincial coaches or supervisors and the central monitoring and evaluation team conducted active data quality assurance at the facility level. The coaches conducted careful review of the data from the facilities, checking for inconsistencies. Any discrepancy was discussed by phone and during the periodic visits to the facilities, and if needed, additional training on how to fill the registries and report data was conducted. The information was used by the MOH (provincial and central levels) and the project to monitor progress and success of the intervention on a quarterly basis.

All of the clinical practice indicators showed marked improvement after the launch of the initiative, as shown in Figs. 9.5 and 9.6, which compared the last quarter reported data each year. Improvements were especially notable for the AMTSL, treatment of preeclampsia or eclampsia with magnesium sulfate, skin-to-skin contact with the mother after delivery, and breastfeeding in the first hour; all four of these indicators exceeded $80 \%$ in 2014. 


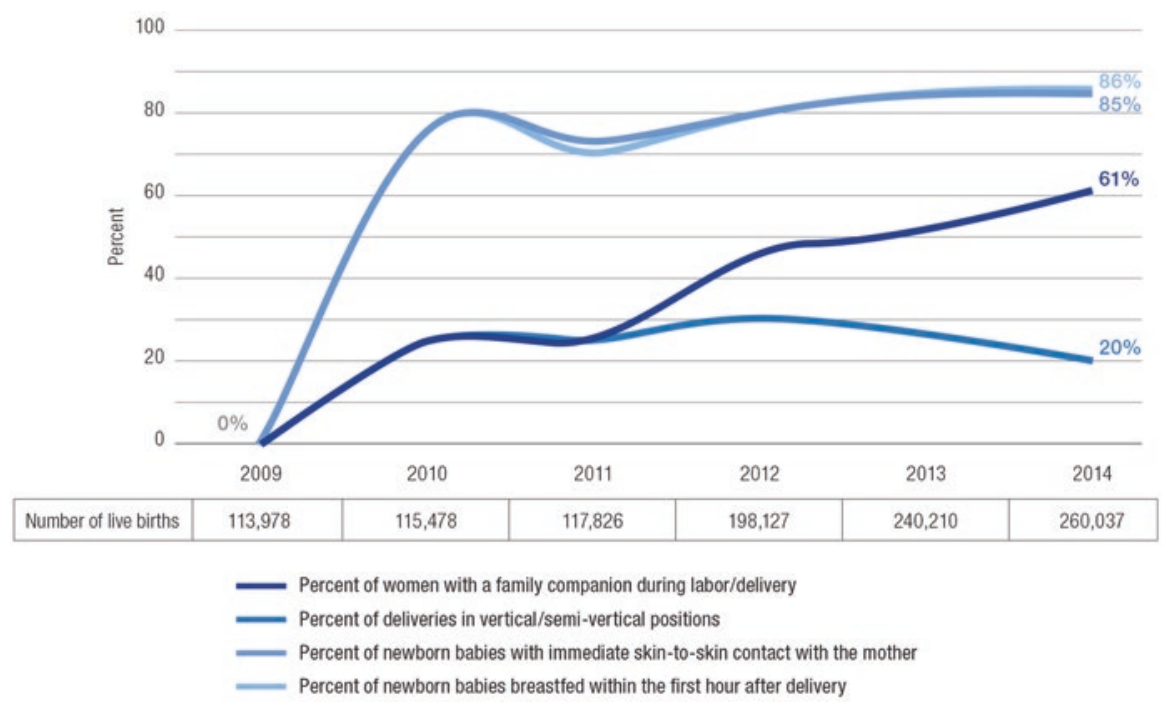

Fig. 9.6 Improvement in respectful care and humanized practices

\section{The Maternal Mortality}

The facility improvement teams used the HMIS to report maternal deaths and analyze institutional maternal mortality each quarter. The same data quality assurance mechanisms were used to verify mortality data. From 2009 to 2014, the institutional mortality ratio reported in the HMIS fell by $46 \%$ - from 416 to 218 deaths per 100,000 live births - in the participating maternities. Mozambique has a 53\% institutional delivery rate, and the MMI covers about one-third of those institutional deliveries. Thus, the initiative should have made an appreciable contribution to reducing the national maternal mortality ratio, which had remained stagnant for several years.

A project technical advisor conducted an independent modeling exercise using the Lives Saved Tool (LiST) (Winfrey et al. 2011). The Lives Saved Tool exercise estimated the impact of the improved coverage of three clinical practices - AMTSL, magnesium sulfate for eclampsia, and use of partograph - on maternal mortality. This modeling exercise predicted a 26\% drop in the institutional maternal mortality ratio from 2009 to 2014 (see Table 9.4). This figure is considerably less than the $46 \%$ decline in the maternal deaths reported by the HMIS, presumably because the HMIS data reflected improvements in a wider array of clinical practices. According to the Lives Saved Tool, 1139 maternal lives were saved during the 5 years of the initiative. 
Table 9.4 The actual maternal deaths at the participating facilities, compared with the estimated impact of the three clinical practices on maternal mortality

\begin{tabular}{l|l|l|l|l}
\hline \multirow{2}{*}{ Year } & HMIS & \multicolumn{2}{l}{ Lives Saved Tool modeling } \\
\cline { 2 - 5 } & Deaths & $\%$ reduction from 2009 baseline & Deaths & $\%$ reduction from 2009 baseline \\
\hline 2009 & 416 & N/A & 416 & N/A \\
\hline 2010 & 406 & $-2 \%$ & 356 & $-14 \%$ \\
\hline 2011 & 433 & $-4 \%$ & 345 & $17 \%$ \\
\hline 2012 & 305 & $-27 \%$ & 306 & $-26 \%$ \\
\hline 2013 & 258 & $-38 \%$ & 316 & $-24 \%$ \\
\hline 2014 & 226 & $-46 \%$ & 308 & $-26 \%$ \\
\hline
\end{tabular}

aLives Saved Tool (LiST) was used to estimate the impact of the improved coverage of the AMTSL, magnesium sulfate for eclampsia, and use of partographs on maternal mortality

\section{The Status of the QI Program}

The MOH said it wanted to continue expanding the implementation of the evidencebased and respectful care practices to all the maternities in the country. However, a USAID independent external evaluation team recommended that follow-on activities of a new maternal and child project should be focused on the two provinces with high maternal mortality in order to accelerate the impact during the next phase. This follow-on project, now in implementation, incorporates additional components, such as, child health, nutrition, immunization, and water and sanitation. The MMI component is a critical element of the new project and expected to reach more facilities in each of the two selected provinces. The MOH continues the implementation of the MMI in the other provinces not currently covered by the project, based on the capacity developed at the provincial level.

\section{Reflection}

The approach to quality improvement used in this effort was the key to the success of the initiative. The approach focused on using the tools that define the performance expectations, placing a focus on immediate action rather than repetitive analysis, stressing formal recognition to increase motivation, and relying on the data collection to document the QI activities.

The approach offered a simple, intuitive, and systematic QI process that was easily understood and well accepted by participants and facilities. It also provided a single tool summarizing recommended practices, which could be utilized throughout the QI process - for internal and external assessments, teamwork and action planning, and for supervision. This reduced the need for external assistance. Appropriate training to disseminate the evidence-based knowledge and practices captured by the assessment tool and to strengthen provider competencies was an essential part of the initiative's foundation. 
Focusing more on action and less time on problem analysis led to rapid change and visible results at the participating facilities (the "low-hanging fruit" approach). This not only empowered and motivated maternity teams but also attracted attention and support from the local and district managers. However, the extent to which facilities adopted the improvement process varied, depending on the factors, such as, local leadership and staff commitment.

The involvement of clients and communities proved to be an effective way to reinforce the change management process, creating a spirit of partnership and accountability. The involvement and support of the $\mathrm{MOH}$ gave legitimacy to the process and helped to mobilize resources for the maternities.

Recognition proved an effective motivator. The facility staff felt honored by the public recognition of their efforts, especially when it came from the high-level authorities, such as, the Minister of Health or Provincial Governor. The nation's First Lady participated in two recognition ceremonies for maternities in provincial hospitals. The high-level policymakers also became more engaged in the MMI through the recognition ceremonies, which offered the $\mathrm{MOH}$ national visibility in the mass media. Other forms of motivation and learning, such as, inter-facility benchmarking, are also proved effective.

Enhanced data collection also contributed to the success of the initiative. The modification of the MOH HMIS provided new information on the indicators of quality-of-care and evidence-based practices that were essential to monitor progress in the short term. In the long term, these indicators were able to document the impact of the QI process on health outcomes. Improvements grew more visible over time, and changes in the key indicators, such as, maternal mortality, only became evident over a period of 5 years.

The gradual expansion of the initiative over the course of 5 years allowed the facilitators and coaches to gain experience in the QI process, resulting in a better planned and organized scale-up of the initiative. The experience in Mozambique demonstrated that often overburdened and poorly motivated providers readily accepted a simple, self-explanatory improvement process. The straightforwardness of the process also helped reduce the need for external assistance, which would have been very expensive when the program reached scale. In addition, the early involvement of the MOH and having it in the "driver's seat" (e.g., the selection of coaches and the integration of the process into the provincial health directorate dynamics) accelerated the scale up of the intervention. As mentioned, on many occasions, provincial authorities expanded the process beyond the donorsupported maternities.

This experience in Mozambique highlights some of the challenges to putting QI in place and suggests potential solutions. Certain critical constraints - notably staff shortages and shortcomings in facility management - created barriers to the adoption and expansion of the MMI. Resolving these issues is important to facilitate the continuing scale up of MMI. One possibility is to develop and implement strategies to further simplify the QI process, for example, by streamlining the tools and making use of the technology-supported job aids, performance support tools, and communication mechanisms. In addition, leaders should also work on guaranteeing 
more human and other resources to maternities adopting the MMI, strengthening facility management, and optimizing service delivery processes.

The MMI in Mozambique shows that it is possible to implement a quality improvement initiative at scale in a low-resource setting, achieving important improvements in the adoption of evidence-based practices and outcomes, such as, institutional maternal mortality. This success was achieved in spite of the severe constraints typical of low-resource settings, including lack of staff, physical plant constraints, and scarcity of other material resources.

Acknowledgement The authors gratefully acknowledge the support of the following individuals for the Model Maternities Initiative in Mozambique: Ministers of Health, Dr. Paulo Ivo Garrido and Dr. Alexandre Manguele; Vice-Minister of Health, Dr. Nazira Abdula; National Directors of Public Health, Dr. Mouzinho Saíde and Dr. Francisco Mbofana; National Directors of Medical Care, Dr. António Mujovo and Dr. Ussene Isse; Associate National Directors of Public Health, Dr. Lidia Chongo and Dr. Quinhas Fernandes; Heads of the Department of Maternal and Child Health, Dr. Nazir Amade, Dr. Munira Abudou, and Dr. Pascoa Wate; Provincial- and District-Level Directors, Ministry of Health from 2009 to 2013; all the midwives, health professionals, and staff of the participating maternities; and staff of the USAID Mission in Mozambique: Polly Dunford, Ana Bodipo, Juno Lawrence Jaffer, Lilia Jamisse, and other officials of the Health, Population, and Nutrition unit.

\section{References}

Ministry of Health (MOH) (2008) Plano Nacional de Desenvolvimento de Recursos Humanos para a Saúde [National Plan for Health Human Resources Development] 2008-2015.

MOH (2016) Plano Nacional de Desenvolvimento de Recursos Humanos para a Saúde [National Plan for Health Human Resources Development] 2016-2025.

Necochea E, Bossemeyer D (2005) Standards-based management and recognition: a field guide. Jhpiego, Baltimore

Winfrey W, McKinnon R, Stover J (2011) Methods used in the Lives Saved Tool (LiST). BMC Public Health 11 Suppl 3:S32

Open Access This chapter is licensed under the terms of the Creative Commons Attribution 4.0 International License (http://creativecommons.org/licenses/by/4.0/), which permits use, sharing, adaptation, distribution and reproduction in any medium or format, as long as you give appropriate credit to the original author(s) and the source, provide a link to the Creative Commons licence and indicate if changes were made.

The images or other third party material in this chapter are included in the chapter's Creative Commons licence, unless indicated otherwise in a credit line to the material. If material is not included in the chapter's Creative Commons licence and your intended use is not permitted by statutory regulation or exceeds the permitted use, you will need to obtain permission directly from the copyright holder.

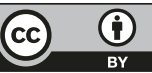

